Developing Transit Station Design Criteria with a Focus on Intermodal Connectivity Author(s): Geophrey Mbatta, Thobias Sando, and Ren Moses

Source: Journal of the Transportation Research Forum, Vol. 47, No. 3 (Public Transit Special Issue 2008), pp. 77-91

Published by: Transportation Research Forum

Stable URL: http://www.trforum.org/journal

The Transportation Research Forum, founded in 1958, is an independent, nonprofit organization of transportation professionals who conduct, use, and benefit from research. Its purpose is to provide an impartial meeting ground for carriers, shippers, government officials, consultants, university researchers, suppliers, and others seeking exchange of information and ideas related to both passenger and freight transportation. More information on the Transportation Research Forum can be found on the Web at www.trforum.org. 


\title{
Developing Transit Station Design Criteria with a Focus on Intermodal Connectivity
}

\author{
by Geophrey Mbatta, Thobias Sando, and Ren Moses
}

The safe and efficient movement of passengers to and from the high-capacity transit system to other modes of transportation is of paramount importance to transportation officials. Transit stations are the primary interfaces for passengers with the transit system. This paper presents a procedure which could be used to develop station design criteria and guidelines with a focus on intermodal connectivity. The proposed procedure may be used for developing station design criteria and guidelines for high-capacity transit systems including rail project and Bus Rapid Transit (BRT). A successful implementation of the transit projects will result in higher ridership rates and hence reduce dependency on automobile driving along Florida highways.

\section{INTRODUCTION}

Accessibility of transit facilities is of paramount importance to transportation officials. The importance is further heightened by the Federal Energy Independence and Security Act of 2007 which urges state and local governments to consider policies designed to accommodate all users, including motorists, pedestrians, cyclists, transit riders, and people of all ages and abilities in order to serve all surface transportation users by creating a more interconnected and intermodal system. The Act further emphasizes the use of environmentally friendly options such as public transportation, walking, and bicycling. Transit stations are the primary interfaces for passengers with the transit system. Adopting a station area facility design which focuses on seamless movement of passengers as they change their modes of transportation at the station would help accomplish safe and efficient movement of passengers as they access and egress the station area.

Different local and state agencies have established their own design guidelines for station facility design. In the state of Florida for example, there are 26 local transit agencies. While all these agencies oversee operation of their local bus system, only two agencies, i.e., Tri-Rail and Miami-Dade County Transit, operate rail systems. Tri-Rail runs the commuter rail system in Palm Beach, Broward, and Miami-Dade counties while Miami-Dade County Transit manages the heavy rail system in Miami-Dade County. Tri-rail, operated by the South Florida Regional Transportation Authority (SFRTA) has published Station Design Guidelines (2004) with criteria for the design and construction of Tri-Rail stations and support facilities. Sections 4 and 5 of the Tri-Rail guidelines provide standards for the station platform design and station amenities. On the other hand, MiamiDade Station design criteria are covered in Volume II of the Miami-Dade County Rapid Transit System Extensions Compendium of Design Criteria (2007).

Florida Department of Transportation (FDOT) districts located in areas with commuter rail systems have established guidelines for the design of transit facilities within their districts. FDOT District 4 published Transit Facility Guidelines (2007) to facilitate engineering details of transit facility design. The primary focus of the District 4 Transit Facility Guidelines is to provide minimum design criteria for transit facilities. District 4 guidelines have more general application with limited guidance for the design of transit station facilities. FDOT District 6 published Facility Planning Guidelines and Design Criteria (1997) specifically for the Miami Intermodal Center (MIC) Project. In anticipation of the proposed future projects such as the Tampa Intermodal Center and Bus Rapid Transit (BRT) in several local jurisdictions within Districts 1 and 7, the two FDOT districts were recently involved in a joint effort to publish the FDOT District 1 and 7 Transit Facility 
Handbook (2007). This handbook provides comprehensive guidance for planning and design of transit facilities, activities, and services for the two districts. The primary focus of the handbook is to provide minimum design criteria for transit facilities with the intent of achieving safety, comfort, and accessibility to passengers. As it is with District 4's guidelines, the District 1 and 7 Guidelines have limited guidance for transit station facilities.

To ensure higher rates of ridership, station areas need to be designed with features known to enhance transit patronage (Porter 1997). The long-term success of transit projects is closely linked to creating connectivity to all modes in the station areas. Of high importance is the station area design which encourages the use of all modes of transportation including pedestrian and bicycle connectivity. Transit stations are often conducive to other public transportation services. Station area principles that promote the use of public transportation in compatibility with private automobiles are also imperative to successful multimodal services.

Although much has been published on design guidelines for transit facilities (rail and BRT systems), none of the examined guidelines were prepared with a focus on intermodal connectivity. In addition, the existing guidelines have more general applications with little guidance for transit station intermodal facilities. This paper discusses the process which can be utilized in developing design criteria and guidelines for transit station intermodal facilities. Design guidelines focusing on intermodal connectivity ensure safety, seamlessness, and comfortable use. This process can be used by a wide range of transit officials including design engineers, land-use planners, and transportation planners from the public and private sectors in planning and designing transit station areas that meet intermodal standards with amenities necessary to encourage all modes of transportation, especially bus and non-motorized modes of transportation. Figure 1 shows a sketch of a typical transit station. The process of developing station design criteria with focus on intermodal connectivity is discussed next.

Figure 1: Sketch of a Typical Transit Station

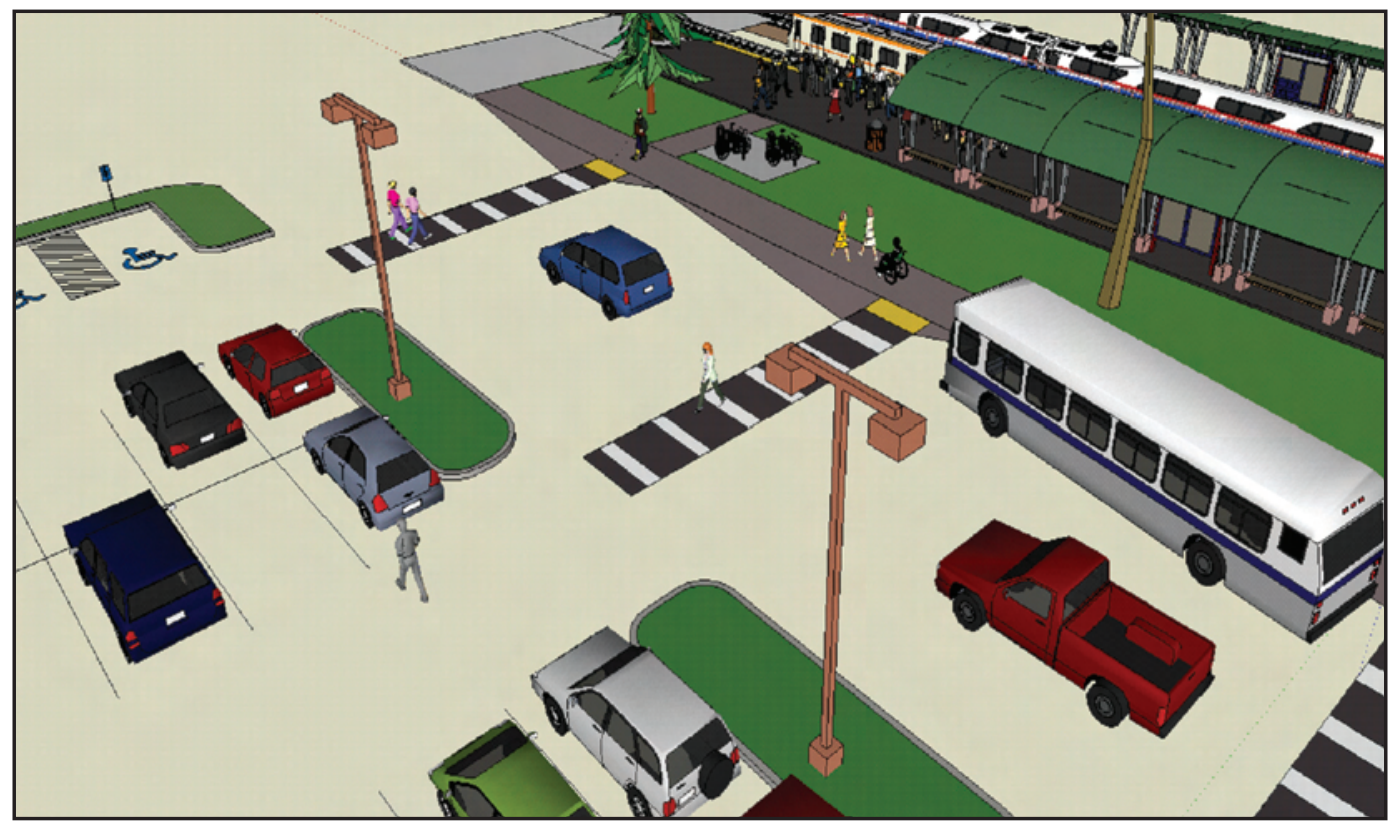




\section{DESIGN CRITERIA DEVELOPMENT PROCESS}

The design process is both applied science and art. The federal government requires compliance to the Americans with Disabilities Act (ADA) for all public facilities, including transit stations. In the last decade, there has been an emphasis on going beyond ADA requirements to universal design principles. Universal design principles promote equitable use of transit systems to all users regardless of their impairments. Clearly, universal design principles do not necessarily provide intermodal connectivity at the transit station. A comprehensive process that would examine intermodal connectivity is needed to provide design guidelines that ensure safety, seamlessness, and comfortable use of passengers. Figure 2 depicts a graphical presentation of the proposed procedure. The presented procedure is discussed in the following sections in details.

Figure 2: Design Criteria Development Procedure

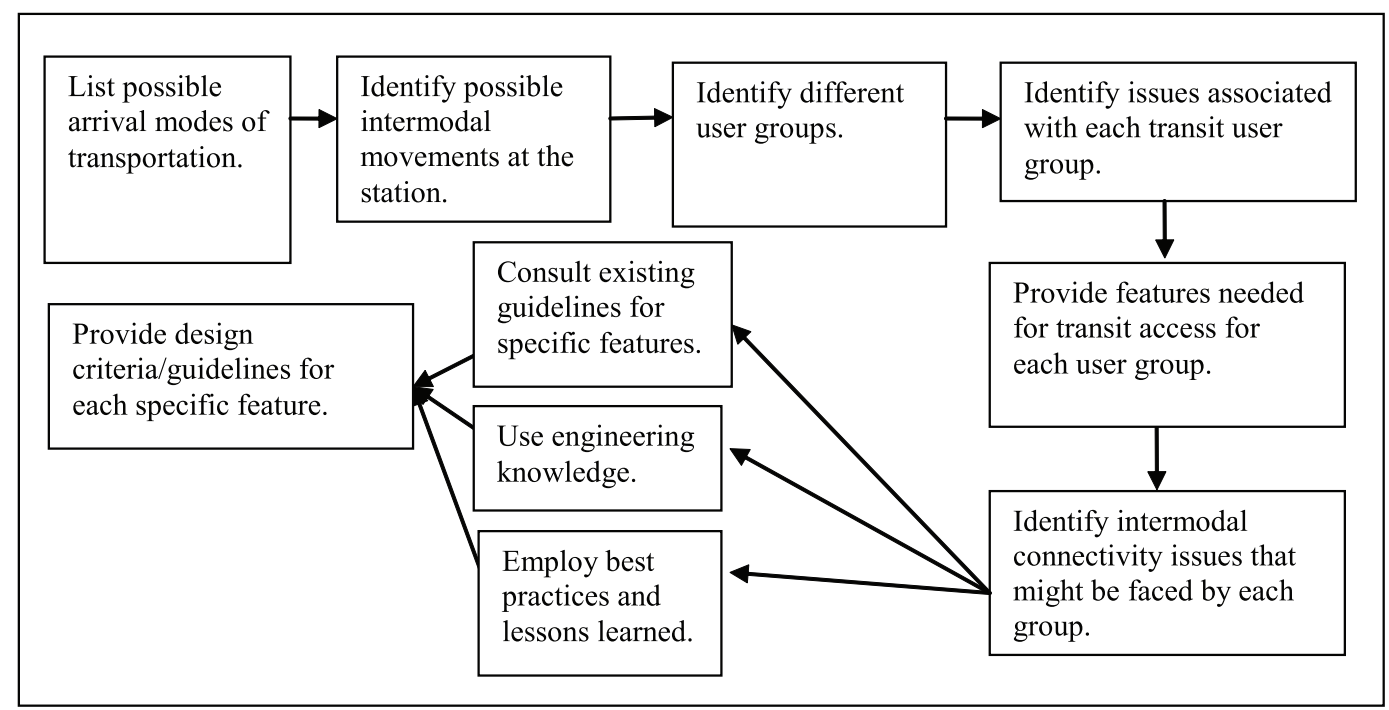

\section{Possible Arrival Modes of Transportation}

Passengers may arrive at a transit station by a variety of means (Figure 3). The means include walking, arriving in a private vehicle, being dropped off from a car, riding a van, riding a feeder bus, using paratransit service, or from another transit mode. Station design should include features necessary for providing access to station by all common modes of transportation. Features such as bus bays for buses and shuttles, kiss-and-ride for drop-off vehicles and paratransit vehicles, park-and-ride for private automobiles, and bicycle racks for cyclists are typically provided for accessibility of the aforementioned arrival modes. Normally, the last mode of transportation before boarding the transit vehicle is walking. Design criteria should ensure seamless and safe movements of pedestrians as they interact with other modes at the station.

\section{Identify Possible Intermodal Movements at the Station}

Common intermodal movements are graphically summarized in Figure 3. Typically, the last mode of transportation before boarding the transit vehicle is walking. By definition, a pedestrian is any person who is afoot or who is using a wheelchair or a means of conveyance propelled by human power other than bicycle. Passengers arriving at the station by modes of transportation other than walking will change modes to the pedestrian mode before accessing a transit vehicle. Passengers riding buses will use a sidewalk/pathway to walk toward the platform after unloading from buses. 


\section{Transit Station Design Criteria}

On the other hand, passengers arriving by private automobiles will have to use crosswalks to cross circulation roads at the park-and-ride facility before reaching the sidewalk on the way to the platform. Provision of transit facilities should ensure seamless, safe, and convenient interaction of all modes of transportation as they access and egress the station.

Figure 3: Arrival Modes at Transit Station

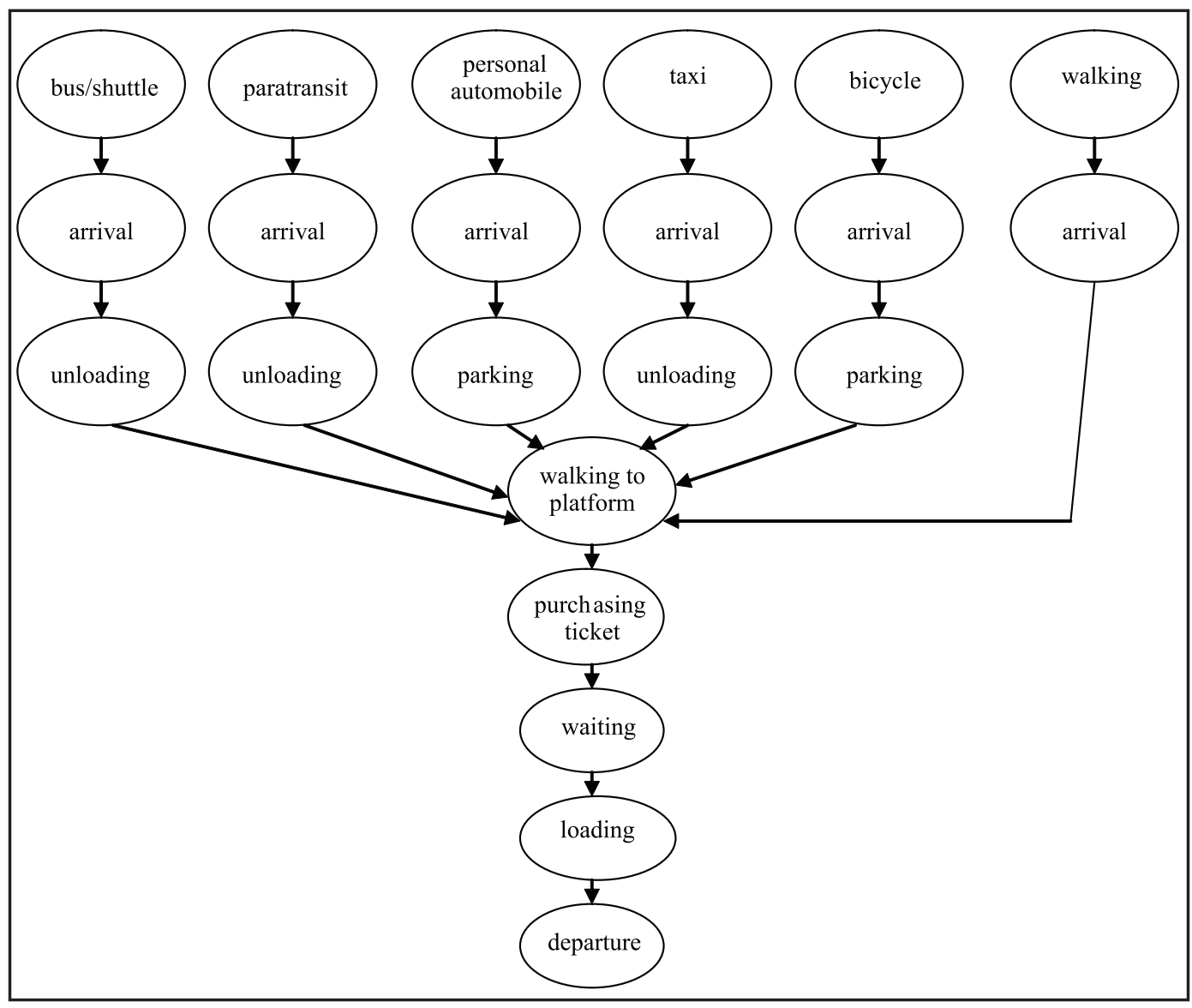

\section{Identify User Groups of Different Modes of Transportation}

ADA requires all facilities built for public use to adhere to the design principle which will not discriminate any person regardless of his/her disability. According to the Literacy Volunteers of America (2000), 13-15\% of Americans are on the lowest literacy level, which is considered as functionally illiterate (those who cannot read or write English). According to the National Health Interview Survey by the National Center for Health Statistics (2008), on average during 2001-2005, almost $30 \%$ of the noninstitutionalized adult U.S. population (approximately 62 million people) had basic actions difficulty. More than one-fifth of the noninstitutionalized adult population reported difficulty with basic movement actions such as walking, bending, reaching overhead, or using their fingers to grasp something. About $13 \%$ of the adult population reported vision or hearing difficulties. Three percent reported cognitive difficulties. According to the report, these statistics vary with demographic characteristics such as age and income, among other factors. Sixty-one percent of the population aged 65 years and over reported difficulty in basic actions while almost $40 \%$ of those with basic actions difficulty reported family incomes below $200 \%$ of the federal poverty threshold, compared with only about one-fourth of nondisabled adults. 
Equitable use of transit facilities is a sensitive issue. Transit users range from able-bodied people who are fit and agile to physically challenged users who suffer from different infirmities. The universal design handbook (2001) categorizes people with limited mobility in eight levels. In level 1 are fit and agile people, those who can run and jump, leap up stairs, and carry loads of heavy baggage. In level 2 are the generality of normal adult able-bodied people who can walk, with flights of stairs not troubling them. Level 3 consists of people who may not be considered as disabled but are of small size/stature, and hence have limited mobility compared to people with normal size. In level 4 are older people who are not perceived as being disabled. By comparison with younger adult people, however, these are people who are commonly prone to discrimination caused by steep steps or stairs without handrails. Also in level 4 are people with infants in strollers. Ambulant people with disabilities are in level 5. People in level 6 are independent wheelchair users while in level 7 are people with disabilities who drive electric scooters and those who use wheelchairs who need another person to facilitate their mobility. The top level (level 8) consists of wheelchair users who need two people to help them when they go out.

Special accommodation is needed for people with vision impairments. Vision impairment spans a continuum, from total blindness at one extreme to partial sight, or low vision, at the other. Other types of impairments include hearing, cognitive, and language impairments. Passengers with more than one type of impairment are faced with even more difficulties in using transit station facilities and amenities. Table 1 summarizes special features that might be needed to facilitate usage of transit station by passengers with different impairments.

\section{Identify Issues Associated with Each Transit User Group}

Design guidelines have to address key accessibility issues associated with each transit user group. Identification of issues associated with each type of impairment is necessary to ensure that stations are designed to accommodate all types of passengers. Table 2 summarizes some common station features and issues faced by each user group.

Table 1: Special Features for Different User Groups

\begin{tabular}{|c|c|c|c|}
\hline Group & Impairment & Physical aid(s) used & $\begin{array}{l}\text { Features needed for } \\
\text { station accessibility }\end{array}$ \\
\hline Mobility 1 & Physically fit & $\mathrm{N} / \mathrm{A}$ & Loading/unloading area \\
\hline Mobility 2 & No use of legs & Wheelchairs, scooters & $\begin{array}{l}\text { Clear path, loading / } \\
\text { unloading area }\end{array}$ \\
\hline Mobility 3 & $\begin{array}{l}\text { Limited strength, } \\
\text { endurance, dexterity, } \\
\text { balance, coordination }\end{array}$ & $\begin{array}{l}\text { Wheelchairs, scooters, canes, } \\
\text { crutches, walkers, seating, } \\
\text { leaning posts, assistants }\end{array}$ & $\begin{array}{l}\text { Clear path, loading / } \\
\text { unloading area }\end{array}$ \\
\hline Visual 1 & Total blindness & Canes, dogs, assistants & $\begin{array}{l}\text { Auditory, tactile surface, } \\
\text { consistency }\end{array}$ \\
\hline Visual 2 & Partial blindness & Canes, dogs, assistants & $\begin{array}{l}\text { Auditory, tactile surface, } \\
\text { Consistency, color, } \\
\text { contrast, lighting }\end{array}$ \\
\hline Hearing & Deafness & Hearing aids & Visual displays \\
\hline Cognitive & $\begin{array}{l}\text { Impaired development, } \\
\text { language, } \\
\text { comprehensive }\end{array}$ & N/A & $\begin{array}{l}\text { Simple language, } \\
\text { consistency, symbols }\end{array}$ \\
\hline $\begin{array}{l}\text { Language } \\
\text { illiterate }\end{array}$ & $\begin{array}{l}\text { Impaired reading, } \\
\text { speaking, lack of } \\
\text { English skills }\end{array}$ & $\mathrm{N} / \mathrm{A}$ & $\begin{array}{l}\text { Simple language, } \\
\text { symbols }\end{array}$ \\
\hline
\end{tabular}




\section{Provide Features Needed for Transit Access for Each User Group}

There are specific features tailored to a specific user group. For example, tactile surfaces are meant to help patrons with visual impairment while ramps are specific to people using mobility aids such as wheelchairs. Table 3 lists specific features meant to facilitate easy movement of passengers with different impairments. Some of the provisions such as tactile surfaces have been blamed to be hazardous to users other than the blind. While it is apparent that such surfaces can be uncomfortable, and sometimes hazardous, the design community is convinced that tactile surfaces are essential for people who are blind, hence the tradeoff is worthwhile.

\section{Identify Interconnectivity Issues That Might be Faced by Each Group}

Transit stations serve as an interface between the transit system and other modes of transportation. The stations are characterized by interaction between various modes of transportation. If not properly designed, interaction between different modes can result in conflicts between modes which might in turn discourage patrons from using the transit system. A station designed with interconnectivity in mind provides a seamless, safe, and convenient movement of patrons as they access and egress the station. Examples of station design which pose interconnectivity issues include but are not limited to (1) a design for which bus stops, park-and-ride, and other facilities are located across a busy street, (2) inefficient park-and-ride configuration, (3) improper wayfinding sign placement and design, (4) designs which do not serve all types of impairments, and (5) inefficient circulation of traffic at the station. Identification of these and many other issues in the process of developing design criteria and guidelines would help eliminate connectivity issues, hence enhance efficiency, safety, and convenience of patrons as they enter and leave the stations. 
Transit Station Design Criteria

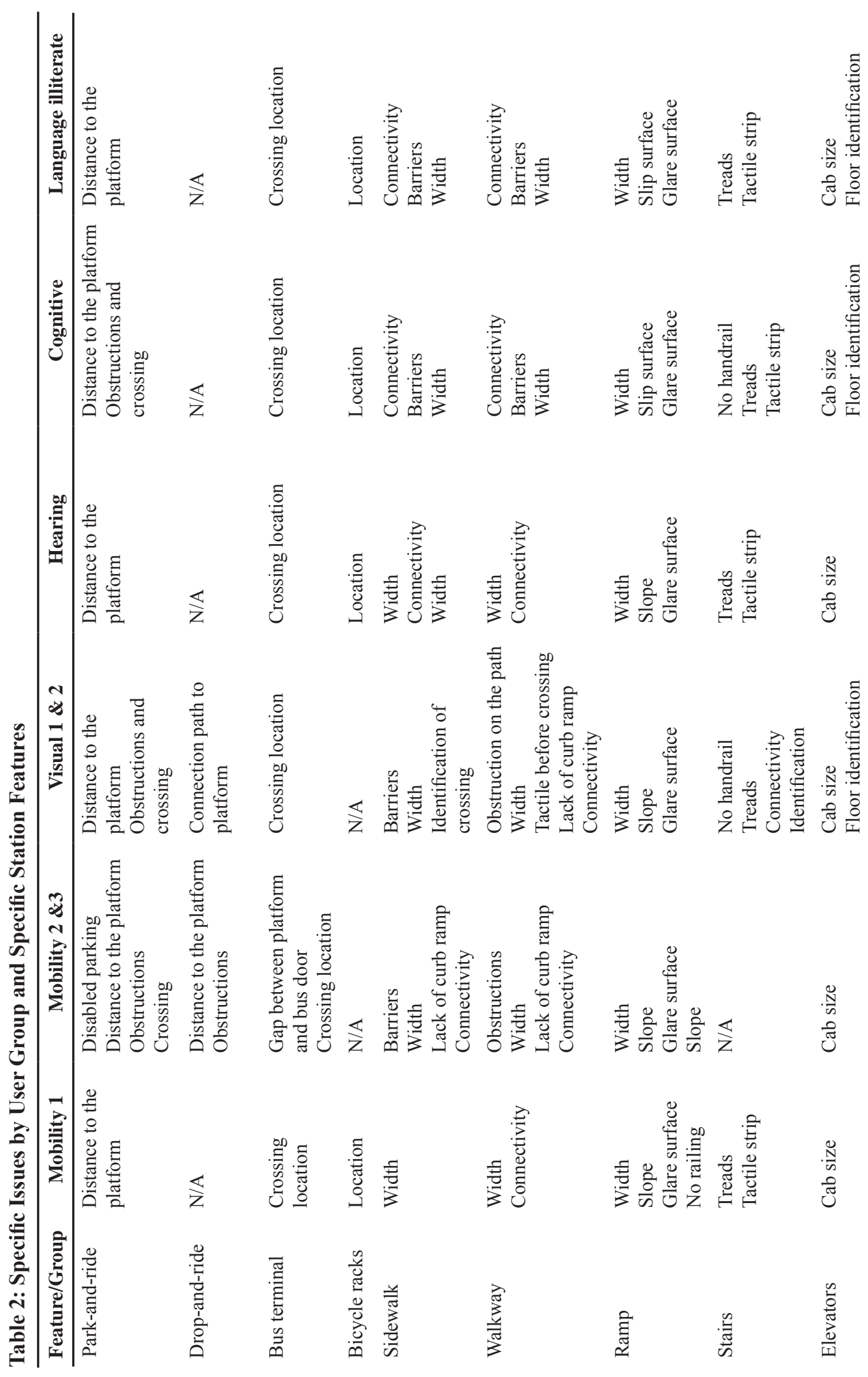


Transit Station Design Criteria

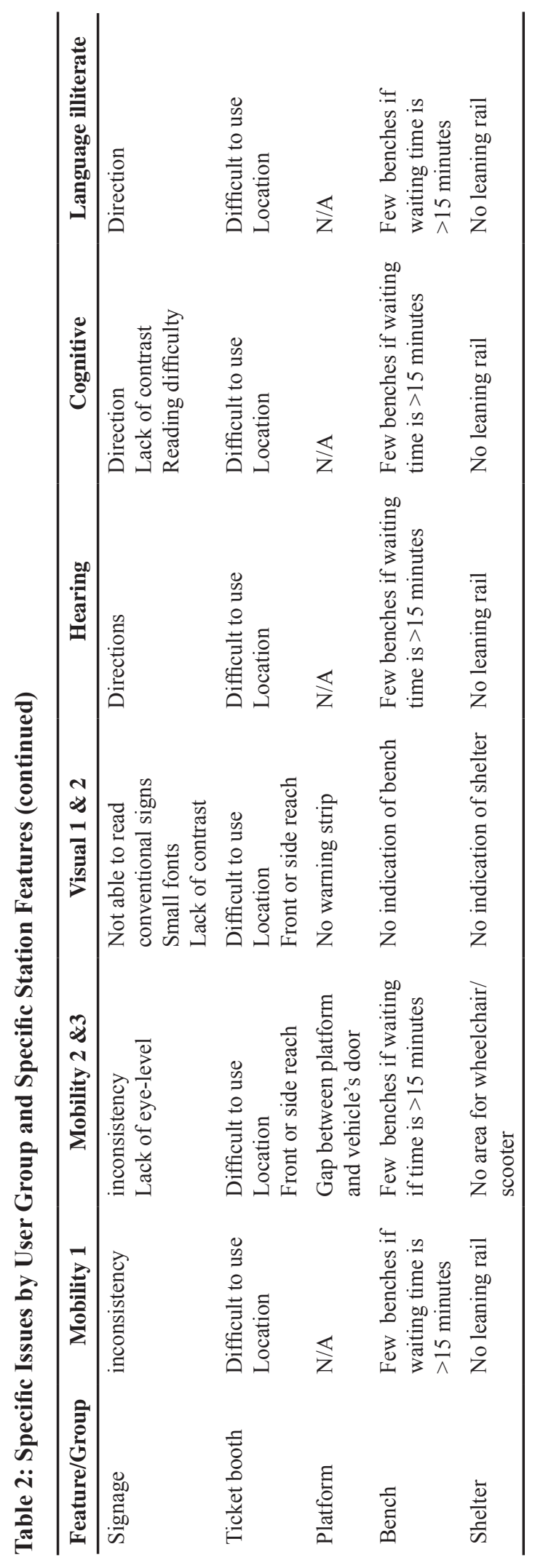




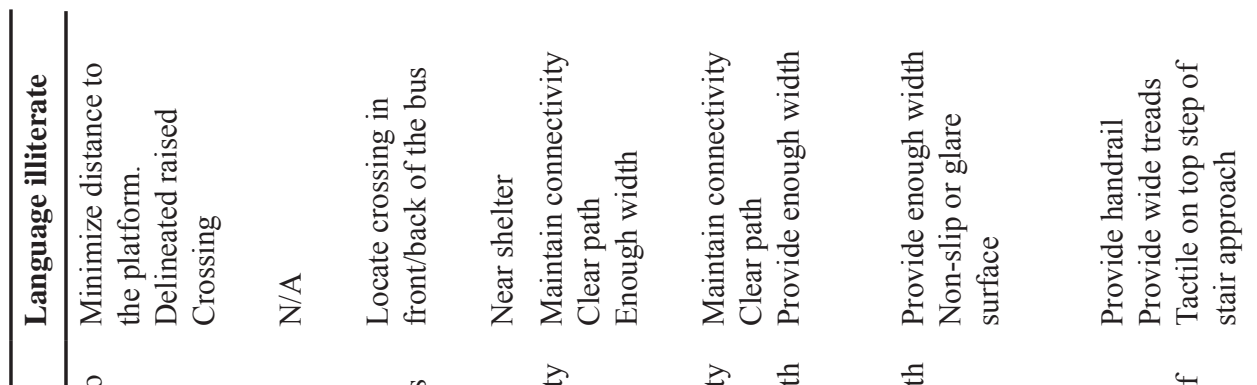

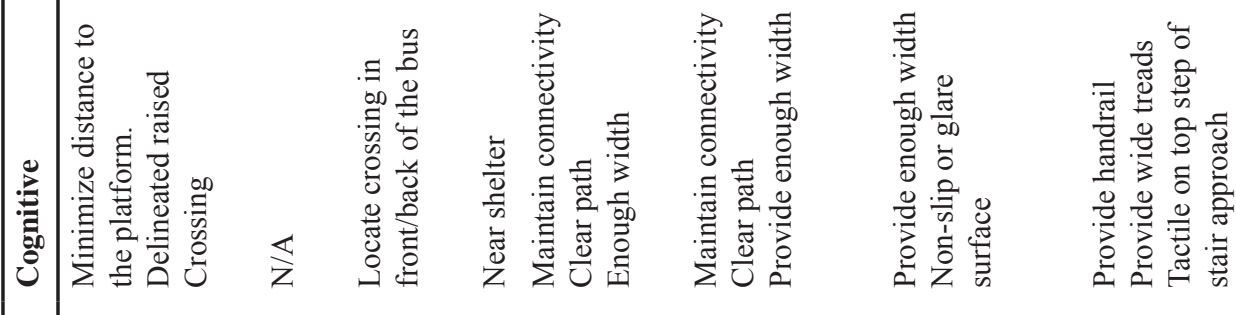

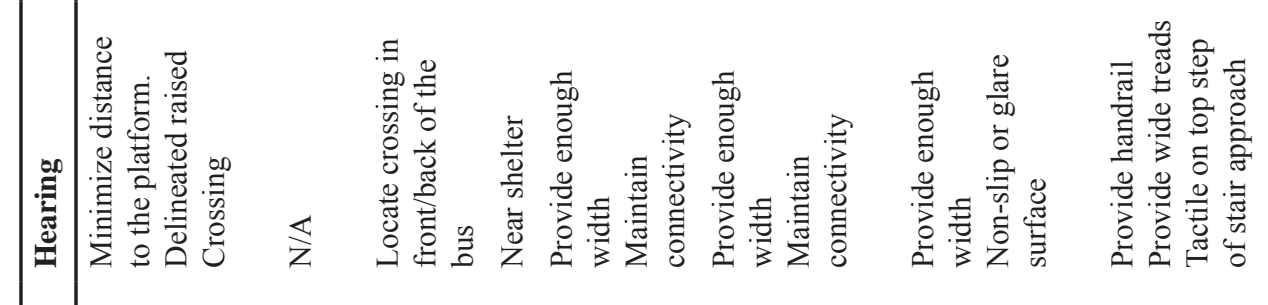

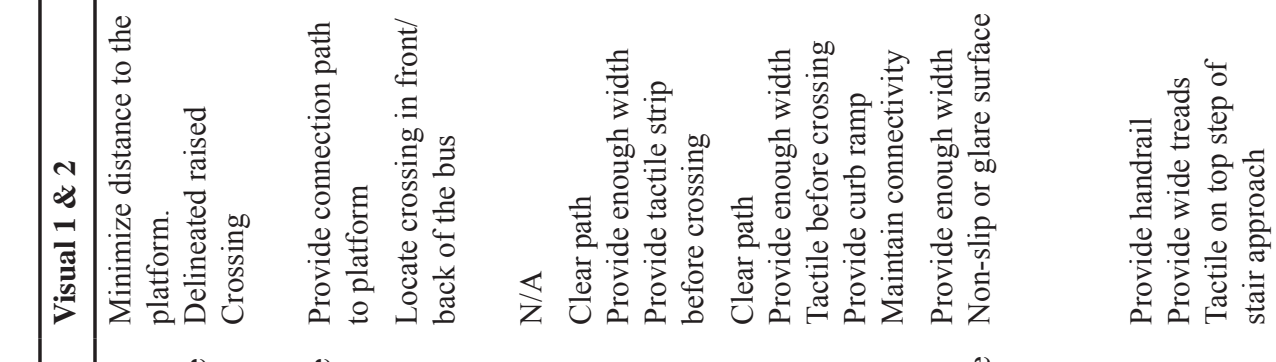

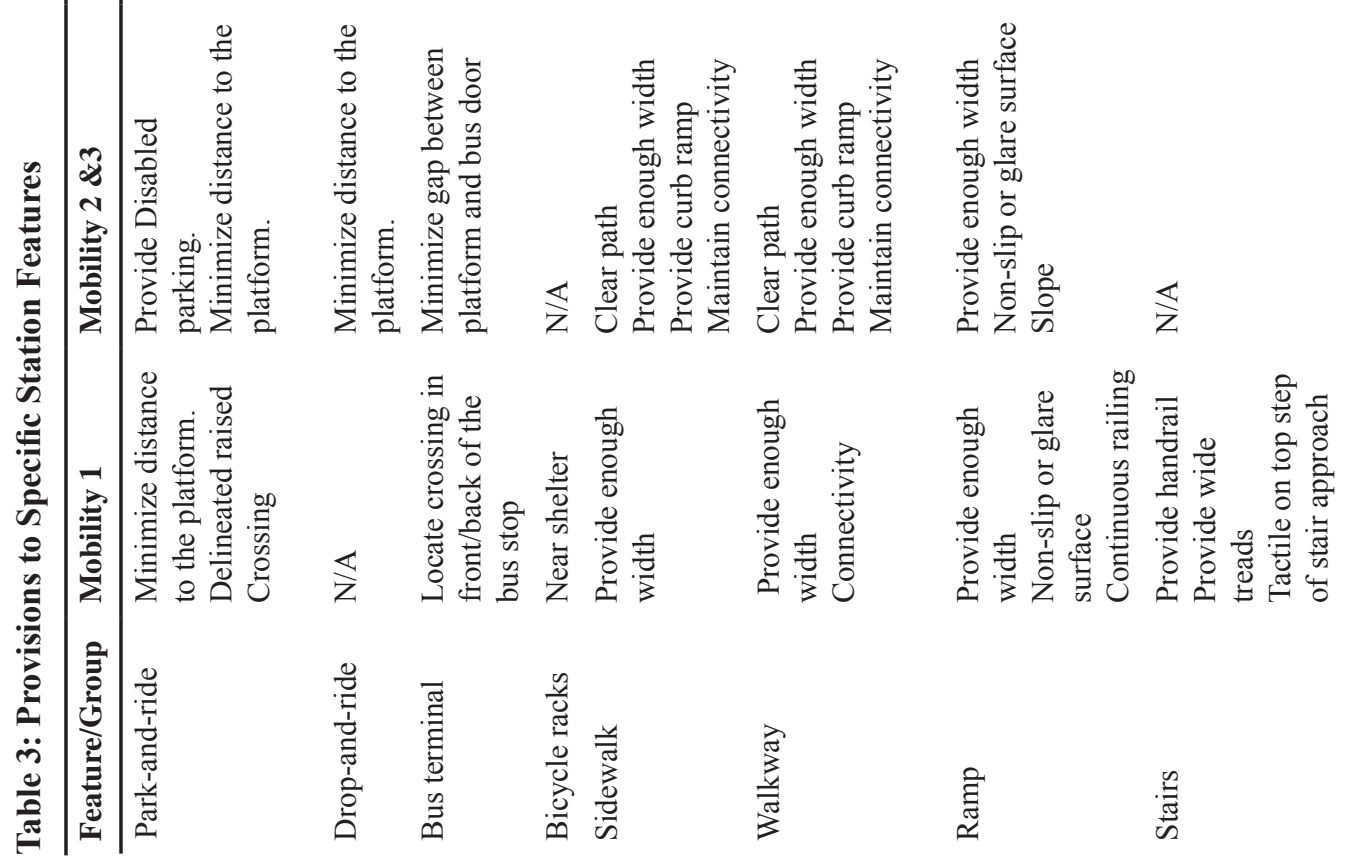


Transit Station Design Criteria

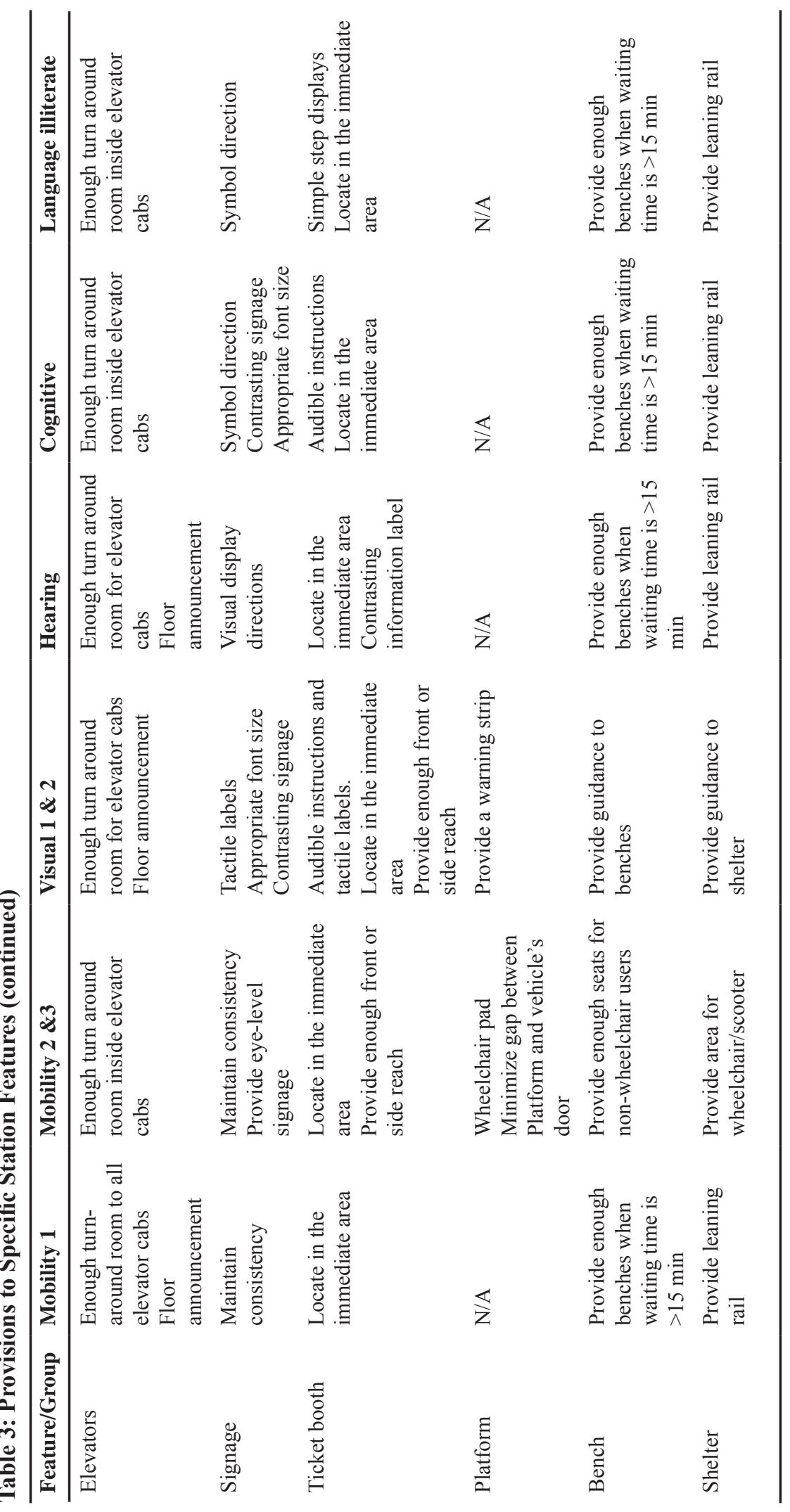




\section{Determination of the Minimum Design Criteria and Guidance}

Station area design must address all accessibility issues faced by each user group as they access and egress stations. There are numerous authoritative design guidelines published by different entities ranging from federal agencies to local authorities. Minimum criteria and recommended practice can be found in these guidelines. In addition to the existing design guidelines, the process of developing transit station design guidelines should utilize the lessons learned and best practices from past experiences. Equally important, the process should involve engineering judgment based on the principles of science and engineering.

Consult Existing Guidelines for Specific Features. There are many existing guidelines prepared by agencies ranging from federal to local jurisdictions. Most of these guidelines are not exclusively transit related but contain clauses and components which need to be adhered to by the design of transit systems. Some of the nationally recognized documents which could be used in developing transit station design criteria and guidelines are discussed next.

Several federal agencies have established guidelines that are often referenced in the design of transit stations. One of the most popular guidelines used is the Americans with Disabilities Act Accessibility Guidelines (ADAAG) for Buildings and Facilities (1994). This report contains technical requirements for accessibility to buildings and facilities with disabilities under the Americans with Disabilities Act (ADA) of 1990. The ADA guidelines are applied in the design, construction, and alteration of facilities. A handbook entitled Accessibility Handbook for Transit Facilities was prepared by the Federal Transit Administration (FTA) in 1992. This handbook provides detailed information to help transit designers and planners to construct and renovate transit facilities so that they are accessible to individuals with disabilities of all types including mobility impairments requiring the use of a wheelchair. This handbook also provides facility accessibility checklists to facilitate compliance with the disabilities act.

The American Association of State Highway and Transportation Officials (AASHTO) has published several guidelines that are used to determine minimum design criteria for intermodal and other highway facilities. AASHTO guidelines include A Policy on Geometric Design of Highways and Streets (2004); AASHTO Guide for Park-and-ride Facilities (2004); and AASHTO Guide for the Planning, Design, and Operation of Pedestrian Facilities (2004). The AASHTO Policy on Geometric Design of Highways and Streets (commonly known as the AASHTO green book) documents the minimum criteria for the design of pedestrian and bicycle facilities such as sidewalks, pedestrian storage islands in intersection medians, and pedestrian signals. It also reports the minimum design criteria for other modes of transportation such as buses, taxis, etc, used in the engineering practice. The AASHTO Guide for Park-and-ride Facilities provides necessary information for the design of parking facilities including minimum criteria necessary for circulation and accessibility. The AASHTO Guide for the Planning, Design, and Operation of Pedestrian Facilities provides guidance on planning, designing, and operations of pedestrian facilities along highways and streets. The manual's primary focus is to provide guidance on how pedestrians can best be accommodated on public right-of-way. It also provides minimum design criteria for accessibility of pedestrian facilities.

The Highway Capacity Manual (HCM) (2000) and its companion the Transit Capacity and Quality of Service Manual (TCQSM) (2003), both published by the Transportation Research Board, are another set of nationally recognized manuals. While the HCM was specifically prepared to provide methods for evaluating quality of service for roadway, pedestrian, and bicycle facilities, the TCQSM is aimed at assisting transportation practitioners to have a consistent set of techniques for evaluating the required capacity and quality of transit services, facilities, and systems.

The Manual of Uniform Traffic Control Devices for Streets and Highways (MUTCD) (2003) published by the Federal Highway Administration defines the standards used to install and maintain traffic control devices on all streets and highways. The research sponsored by the Transit 
Cooperative Research Program (TCRP) produced the Guidelines for Transit Facility Signing and Graphics (1996), also known as TCRP Report 12. The report describes the use of signs and symbols that provide for the safe and efficient movement of passengers to and through transit facilities. The general format of the report was developed to lead transit providers through the entire process from wayfinding design to actual installation of the signs. Several versions of common symbols in English, Spanish, French, German, Italian, Korean, and Chinese are listed in the report. The report further discusses the ability of symbols to communicate meaning in various languages.

Apart from the federal agencies, nationwide transit providers such as Amtrak and Greyhound have established guidelines for the design of their station facilities. Amtrak, which stands for "American" and "track," is operated by the National Railroad Passenger Cooperation and provides intercity passenger transportation service. The Amtrak Station Manual (2001) has standards and guidelines for pedestrian access and circulation, vehicular access and circulation, and train information signage, among other station features. Some stations have connections to intercity bus transportation. Greyhound Lines Inc. is the largest provider of intercity bus transportation across North America. Greyhound guidelines (2004), also known as sizing documents, provide guidance on geometric features necessary to accommodate Greyhound buses, passenger accessibility, and bus terminal survey forms to ensure compliance to design standards.

Employ Best Practices and Lessons Learned. Best practices and lessons learned have been documented by numerous studies. While best practices would identify recommended practices, lessons learned would provide information on practices that need to be avoided based on past experience. For example, the study that was performed by Spillar (1997) recommended that it is important for the loading bay to be perpendicular to the parking lot to motivate good usage of available walkways and prevent the tendency of pedestrians to take shortcuts. The study that was performed to establish the Guide for the Design of Park-and-Ride Facilities (2004) recommended a raised pedestrian path above the driving surface because, apart from delineating a pedestrian crosswalk, it also acts as a speed hump.

Use Engineering Knowledge. The use of established guidelines and best practices should be complemented by a sound engineering knowledge. One example where the engineering knowledge could be used is on setting the maximum walking distance to the parking lot. For example, according to O'Sullivan and Morrall (1996), the general walking distance guideline is that the person will walk a maximum of about five minutes to reach the bus stop at light-rail transit stations. An average pedestrian walking speed of 4 feet per second is typically used for designing roadway facilities (HCM 2000; MUTCD 2003; AASTHO 2004). A walking speed of three feet per second is commonly used for the elderly population. Using engineering knowledge and equations of motion, these recommended design speeds with the general guideline of five minutes would result in a maximum walking distance of about 900 to 1,200 feet. Engineering knowledge of traffic conflicts and human factors in engineering design could also be used in providing guidelines of transit station facilities.

\section{Provide Minimum Design Criteria/Guidelines for Each Specific Feature}

Design criteria and guidelines can be presented in a variable formats. The Design Handbook for Florida Bus Passenger Facilities (2004), for example, presents design guidelines by describing three design elements -1 ) purpose, 2) location factors, and 3) design factors. In contrast, the Federal Highway Administration (FHWA) Pedestrian Road Safety Audit Guidelines and Prompt Lists (2007) uses prompt lists to provide guidance on the pedestrian road safety audit process. For each particular prompt, a detailed description of each prompt is given followed by the road safety audit example. The detailed description of the prompts includes 1) problem description to include situations where issues arise and potential specific consequences, 2) special considerations for the 
road safety audit team, and 3) photographs illustrating the problem. Other agencies, such as the Easter Seals Project Action (2008), uses a compliance checklist to ensure adherence to the design minimum criteria. Conversely, other guidelines, such as the British Colombia Municipal Systems Program Design Guidelines for Accessible Bus Stops (2007), lists design guidelines in point format. The British Colombia guidelines present the minimum criteria in bolded font while other guidelines are presented in normal font.

\section{CONCLUSIONS AND RECOMMENDATIONS}

Transit stations are locations where transit passengers change modes from transit to other modes of transportation including pedestrian, bicycling, automobile, and other transit modes. If transit stations are not well-designed, the interaction between different modes may pose safety concerns. Additionally, poor connections of modes at the stations may result in inefficient station operation and undesirable service which may hinder patrons from using transit systems. The safe and efficient movement of passengers to and from the train to other modes of transportation is of paramount importance to transportation officials. Transit stations are the primary interfaces for passengers with the transit system. Adopting a station design criteria and guidelines which focus on seamless movement of passengers as they change their modes of transportation at the station would help accomplish safe and efficient movement of passengers as they access and egress the station area.

This paper has presented a procedure which can be used in developing the transit station design criteria and guidelines which focuses on intermodal connectivity. The procedure proposed in this paper is inclusive of all user groups, including people with disabilities. The proposed process will be a valuable resource to planners, engineers, and other transportation officials responsible for developing guidelines and criteria used for evaluating new and existing designs of transit stations.

\section{References}

American Association of State Highway and Transportation Officials. A Policy on Geometric Design of Highways and Streets. Washington, D.C., 2004.

American Association of State Highway and Transportation Officials. Guide for the Design of Parkand-Ride Facilities. Washington, D.C., 2004.

American Association of State Highway and Transportation Officials. Guide for Planning, Design and Operation of Pedestrian Facilities. Washington, D.C., 2004.

AMTRAK Inc. AMTRAK Station Manual-Station Program and Planning: Standards and Guidelines. Version 1.2, 2001.

British Columbia Transit Municipal Systems Program. Design Guidelines for Accessible Bus Stops. Retrieved March 23, 2008, from www.bctransit.com/corporate/resources/pdf/res-urban-21.pdf.

Easter Seals Project ACTION http://www.keystationsurvey.org/compliance1.cfm. Retrieved February 2008.

Federal Highway Administration, Manual on Uniform Traffic Control Devices (MUTCD), 2003.

Florida State University. Design Handbook for Florida Bus Passenger, Facilities: Accessing Transit. Department of Urban and Regional Planning - Florida Department of Transportation, Public Transit Office, 2004.

Florida Department of Transportation, District 4, Transit Facilities Guidelines. $3^{\text {rd }}$ Version, October 2007. 
Transit Station Design Criteria

Florida Department of Transportation, Districts One and Seven, Transit Facility Handbook. 2007.

Florida Department of Transportation District 6, Miami Intermodal Center: Facility Planning Guidelines and Design Criteria, 1997.

Greyhound Inc. Sizing Document. Design and Construction Department, 2004.

Literacy Volunteers of America. Facts on Illiteracy in America, 2000.

Miami-Dade County Transit. Rapid Transit System Extensions Compendium of Design Criteria. Volume II. Station Design Criteria, 2007.

National Center for Health Statistics. Disability and Health in the United States, 2001-2005. Hyattsville, MD, 2008.

O'Sullivan, S. and J. Morrall. "Walking Distances To and From Light-Rail Transit Stations." Transportation Research Record 1538, (1996): 19-26.

Porter, D.R. Synthesis of Transit Practice 20. Transit Cooperative Research Program. Washington, D.C., 1997.

Preiser, W.F.E., \& E. Ostroff. Universal Design Handbook. McGraw-Hill, New-York, 2001.

South Florida Regional Transportation Authority. Tri-Rail Design Guideline and Specification: Station Design Guideline, 2004.

Transit Cooperative Research Program, Guidelines for Transit Facility Signing and Graphics. Report 12, 1996.

Transit Cooperative Research Program, Transit Capacity and Quality of Service Manual. $2^{\text {nd }}$ Edition, Report 100, 2003.

Transportation Research Board, Highway Capacity Manual, 2000.

U.S. Department of Transportation, Federal Highway Administration, Pedestrian Road Safety Audit Guideline and Prompt List, 2007.

U.S. Architectural and Transportation Barriers, Americans with Disabilities Act (ADA): Accessibility Guidelines for Building and Facilities, 1990.

U.S. Department of Transportation, Federal Transit Administration, Accessibility Handbook for Transit Facilities, 1992.

Washington State Department of Transportation. Incorporating Pedestrians into Washington's Transportation System: Pedestrian Facilities Guidebook, 1997. 
Mr. Geophrey Mbatta is an assistant researcher and masters degree student at the Florida State University. He conducts research in the area of transportation engineering. His research interests include intermodal facility design, highway safety, and traffic simulation.

Dr. Thobias Sando is an assistant professor at the University of North Florida in Jacksonville, Florida. He teaches and conducts research in the area of transportation engineering. His research interests include intermodal facility design, highway safety, intelligent transportation systems and traffic simulation.

Dr. Ren Moses is an associate professor of civil engineering at the FAMU-FSU College of Engineering where he teaches undergraduate and graduate courses in transportation and traffic engineering. His research interests include intelligent transportation systems, highway safety, roadway design, and multimodal transportation systems. 